\title{
Impact of the carbonisation temperature on the activation of carbon fibres and their application for hydrogen storage
}

\author{
M. Kunowsky ${ }^{1,2}$, B. Weinberger ${ }^{2}$, F. Lamari Darkrim ${ }^{2}$, F. Suárez-García ${ }^{1}$, D. Cazorla-Amorós ${ }^{1}$ and A. Linares- \\ Solano ${ }^{1, *}$ \\ ${ }^{1}$ University of Alicante, Dept. Química Inorgánica, Apartado de Correos 99, E-03080 Alicante, Spain \\ ${ }^{2}$ CNRS LIMHPUPR1311, Université Paris 13, 99 Av. J.B. Clément, 93430 Villetaneuse, France
}

\begin{abstract}
Porous materials are gaining interest due to their potential for storing hydrogen via physisorption. In the present work, two carbon fibres, carbonised at $973 \mathrm{~K}$ and $1273 \mathrm{~K}$, have been chemically activated with $\mathrm{KOH}$ and $\mathrm{NaOH}$, in order to obtain materials with optimised characteristics for hydrogen storage application. Highly microporous activated carbon fibres were obtained from both precursors, especially from the fibre carbonised at the lower carbonisation temperature, remarking its importance on its subsequent activation process. As activation agent, $\mathrm{KOH}$ is more effective for developing the narrow microporosity, and higher yields are obtained. $\mathrm{H}_{2}$ adsorption isotherms were measured at $298 \mathrm{~K}$ for pressures up to $20 \mathrm{MPa}$, and at $77 \mathrm{~K}$ up to $4 \mathrm{MPa}$. The maximum excess adsorption of hydrogen reached $1 \mathrm{wt} .-\%$ at $298 \mathrm{~K}$ and $3.8 \mathrm{wt} .-\%$ at $77 \mathrm{~K}$. The total volumetric storage capacity is of $17 \mathrm{~g} / 1$ at $298 \mathrm{~K}$, and $32 \mathrm{~g} / 1$ at $77 \mathrm{~K}$.
\end{abstract}

Keywords: hydrogen adsorption; activated carbon fibres; carbonisation temperature; chemical activation.

\section{Introduction}

In order to use hydrogen as an energy carrier in mobile applications, some obstacles have yet to be overcome. One of the problems is to find a suitable method for hydrogen storage [1]. A promising alternative is to store supercritical hydrogen by means of physical adsorption on porous adsorbents [2-4]. Highly porous carbon materials can be obtained by chemical activation with $\mathrm{KOH}$ and $\mathrm{NaOH}[5,6]$, and their suitability for hydrogen storage has been demonstrated [7-9]. Very recently, Maciá-Agulló et al. demonstrated that porosity which is developed by chemical activation with hydroxides is highly dependant on the crystallinity of the carbon raw material [10]. The study revealed that, under similar boundary conditions, materials of low nanostructural order

\footnotetext{
${ }^{*}$ Corresponding author. Tel.: +34 965903545; fax: +34 965903454.

E-mail address: linares@ua.es
} 
are easier activated by hydroxides than materials which exhibit higher crystallinity [10]. It is known that for carbonised materials the nanostructural order increases with the carbonisation temperature [11].

The subject of the present work is to investigate the activation of carbon fibres (CFs) and their application as hydrogen storage materials. Thereby, special attention is paid to the impact of the raw material's carbonisation temperature on the porosity development of the synthesised material.

\section{Experimental}

\subsection{Activation conditions}

As starting materials, two commercial coal-tar-pitch-based CFs, supplied by Osaka Gas Co., Ltd (Osaka, Japan), Donacarbo S-241 (carbonised at $1273 \mathrm{~K}$ ) and Donacarbo SL-242 (carbonised at $973 \mathrm{~K}$ ), were used. Before the activation, $2 \mathrm{~g}$ of CFs were physically mixed with corresponding amounts of $\mathrm{KOH}$ or $\mathrm{NaOH}$ pellets (Panreac Chemicals, Barcelona, Spain) and then introduced into a horizontal furnace. The furnace was heated at a rate of $5 \mathrm{~K} / \mathrm{min}$, up to the maximum temperature of $1023 \mathrm{~K}$ which was then held constant for $75 \mathrm{~min}$. The thermal treatment was conducted under a constant nitrogen gas flow of $500 \mathrm{ml} / \mathrm{min}$. In order to remove remaining byproducts, the obtained material was repeatedly washed and vacuum filtered, first with a $5 \mathrm{M}$ solution of $\mathrm{HCl}$ and subsequently with distilled water. Finally, the synthesised activated carbon fibres (ACFs) were dried at $383 \mathrm{~K}$ for $24 h$.

\subsection{Characterisation}

The porous structure of the investigated materials was characterised by adsorption of $\mathrm{N}_{2}$ at $77 \mathrm{~K}$, and of $\mathrm{CO}_{2}$ at 273K, using an automated volumetric system (Quantachrome Autosorb-6). Beforehand, the samples were outgassed at $523 \mathrm{~K}$ under vacuum for 4 hours. The DR (Dubinin-Radushkevich) equation was applied to the $\mathrm{N}_{2}$ isotherms for calculating the total micropore volumes [12], and to the $\mathrm{CO}_{2}$ isotherms in order to obtain the narrow micropore volumes (micropores smaller than $0.7 \mathrm{~nm}$ ) $[13,14]$. From the $\mathrm{N}_{2}$ adsorption data also the apparent BET surface areas were obtained.

For measuring the packing densities, approximately $0.5 \mathrm{~g}$ sample were introduced in a press, and the sample volume was measured upon applying a pressure of $550 \mathrm{~kg} / \mathrm{cm}^{2}$. Hydrogen adsorption was measured in two different setups. For hydrogen isotherms at $77 \mathrm{~K}$ and up to $4 \mathrm{MPa}$ a DMT microbalance was used. The samples were degassed at $423 \mathrm{~K}$ for $4 \mathrm{~h}$ under vacuum, and the obtained results were corrected taking into account the buoyancy effect on the sample as well as on the corresponding parts of the microbalance. Measurements at room 
temperature and pressures up to $20 \mathrm{MPa}$ were carried out using a fully automated volumetric apparatus, designed and built up in the University of Alicante. Before every measurement, the samples were degassed at $423 \mathrm{~K}$ for $4 \mathrm{~h}$ under vacuum. After that, the sample was located in the sample holder, and then evacuated at $403 \mathrm{~K}$ during another 4 hours in vacuum. A more detailed description of the equipments can be found in reference [8].

\section{Results and discussion}

As pointed out above in the experimental section, the activation processes were performed under similar conditions, the variables studied being the CFs's carbonisation temperature, the nature of the hydroxide and the hydroxide-to-fibre ratios. Details concerning the porosity development due to activation as well as the resulting yield values are presented in Table 1.

\subsection{Fibres carbonised at $1273 K$ (Donacarbo S-241)}

Several activation processes with $\mathrm{KOH}$ were made using hydroxide-to-fibre ratios of $3: 1,4: 1,6: 1$, and 10:1. Thereby the yield values for the process continuously decreased from 74 to 34 wt.- $\%$. The $\mathrm{N}_{2}$ isotherms are indicated by filled symbols in Fig. 1 . With increasing the ratio the total amount of adsorbed $\mathrm{N}_{2}$ increases, and a higher apparent surface area is developed. For low ratios the materials are essentially microporous and show type I isotherms, according to the IUPAC recommendations [15]. The isotherms are highlighted by a very steep, abrupt ascent of the curve at low relative pressures and the early reaching of a plateau at higher pressures, whereupon no further significant $\mathrm{N}_{2}$ adsorption occurs. With increasing $\mathrm{KOH}$-to-fibre ratio the knee of the isotherm widens, and the plateau shifts to higher pressures, indicating that the pores are widened. The microporosity first increases and reaches its maximum value $\left(0.89 \mathrm{~cm}^{3} \mathrm{~g}^{-1}\right)$ for a ratio of $6: 1$. Further increase to a ratio of 10:1 decreases the micropore volume and some mesoporosity is developed. This is indicated by both, the significant widening of the knee as well as a beginning hysteresis formation, which indicates capillary condensation of $\mathrm{N}_{2}$ [15]. The micropore volume for narrow micropores smaller than $0.7 \mathrm{~nm}$ has its maximum for a ratio of $6: 1$, reaching $0.65 \mathrm{~cm}^{3} \mathrm{~g}^{-1}$. Upon further enhancing the amount of activation agent up to a ratio of 10:1 the total micropore volume decreases only slightly, whereas the value for narrow microporosity drops significantly, reaching with $0.53 \mathrm{~cm}^{3} \mathrm{~g}^{-1}$ its lowest value.

Activations with $\mathrm{NaOH}$ as activation agent were made using hydroxide-to-fibre ratios of 4:1 and 10:1. The corresponding $\mathrm{N}_{2}$ adsorption isotherms are also shown in Fig. 1, indicated by empty symbols. The values of apparent BET surface area and total microporosity are higher than the values that are obtained for the 
corresponding activations with $\mathrm{KOH}$. For the 4:1 ratios only slight differences in the shapes of the isotherms can be seen. The isotherm of the $\mathrm{NaOH}$ activated fibre has a wider knee, the plateau is reached at higher pressures, and more $\mathrm{N}_{2}$ is adsorbed. The differences for the 10:1 ratios, on the other hand, are very significant. The isotherm of the $\mathrm{NaOH}$ activated fibres indicates a high amount of mesopores in this material, due to the continual rising curve without plateau and a hysteresis loop, whereas the $\mathrm{KOH}$ activated sample has a low amount of mesopores. According to the IUPAC recommendations the shape of the $\mathrm{NaOH}$ isotherm is a combination of type I (at low relative pressures) and IV (at intermediate and high relative pressures) [15]. The yield values for the $\mathrm{NaOH}$ activated fibres are considerably lower than those obtained for $\mathrm{KOH}$ activation, a fact that is particularly important with respect to an economic viewpoint and for the cost-efficient production of large amounts of activated fibres. From this viewpoint, the activation with a $\mathrm{NaOH}$-to-fibre ratio of 10:1 does not seem to be appropriate, since a yield of only $6 \mathrm{wt} .-\%$ is obtained.

The results of the chemical activation of coal-tar-pitch-based fibres carbonised at 1273K (S-241) support findings in the literature, where the same raw material was used for activation [16]. In this low crystallinity carbon fibre precursor $\mathrm{NaOH}$ activation leads to a higher porosity development than $\mathrm{KOH}$. On the other hand, the activation with $\mathrm{KOH}$ is more selective, producing mainly small micropores, and a narrower pore size distribution. The yield values are better for activations with $\mathrm{KOH}$, especially when activations with high hydroxide-to-fibre ratios are compared.

\subsection{Fibres carbonised at $973 K$ (Donacarbo SL-242)}

The CFs, produced at a lower carbonisation temperature, were activated with $\mathrm{KOH}$ using hydroxide-to-fibre ratios of $2: 1,3: 1,4: 1$, and $5: 1$. Interestingly, it turns out that such relatively small hydroxide-to-fibre ratios are sufficient for the synthesis of highly porous materials. With increasing ratios the yield values diminish from 80 to $55 \%$. The $\mathrm{N}_{2}$ adsorption isotherms are shown in Fig. 2 and reveal a uniform pattern. It shows that the amount of adsorbed $\mathrm{N}_{2}$ increases consistently with increasing hydroxide-to-fibre ratio, due to a growing porosity. Both the BET value and the micropore volume rise, a fact which is supported by the observation that all isotherms are essentially microporous. Although a widening of the isotherm knee occurs, no evidence for mesopore formation can be found, even for the highest ratio that was used in this study. While the mean pore size increases with higher ratios, also the amount of small pores increases continuously. Unlike the total micropore volume, the volume of narrow micropores calculated from $\mathrm{CO}_{2}$ adsorption does not follow a clear trend. However, it remains 
on a throughout high level, and all values exceed or equal those that are measured for the activated S-241 carbon fibre materials.

Activations with $\mathrm{NaOH}$ were conducted using hydroxide-to-fibre ratios of $2: 1$ and 4:1. Their $\mathrm{N}_{2}$ adsorption isotherms are situated very close to those of their $\mathrm{KOH}$ activated counterparts, and also the corresponding BET values lie in the same range. On the other hand, the isotherms obtained from the $\mathrm{NaOH}$ activated fibres have wider knees, and consequently their total micropore volumes are lower. Also the micropore volumes for narrow micropores are considerably lower than those obtained by $\mathrm{KOH}$ activation.

\subsection{Hydrogen adsorption}

Promising samples were selected from the activations of each kind of precursor, in order to compare their hydrogen adsorption capacities at $298 \mathrm{~K}$ and $77 \mathrm{~K}$. The selection was based on findings from other publications, which investigated relations between the porous structure of the adsorbent and its hydrogen adsorption capacity [7,8,17-20]. In a recent study, it was concluded that for hydrogen storage at room temperature both, high micropore volume as well as narrow pore size distribution, are important and that for pressures up to $20 \mathrm{MPa}$ small micropores are beneficial [8]. On the other hand, the micropore distribution does not play an important role for hydrogen storage at $77 \mathrm{~K}$ and pressures up to $4 \mathrm{MPa}$, and the capacity exclusively depends on the total micropore volume [8]. Another factor that was taken into account for the selection is the yield of the activation process, which has a direct influence on the cost-efficiency of a potential industrial production-process of the activated carbon fibre material.

For hydrogen adsorption measurements at $298 \mathrm{~K}$ the S-241 fibre that was activated using a 6:1 KOH-to-fibre ratio was chosen. From all activations which used this high-temperature-carbonised precursor it revealed the highest $\mathrm{CO}_{2}$ micropore volume $\left(0.56 \mathrm{~cm}^{3} \mathrm{~g}^{-1}\right)$, a narrow pore size distribution, and an acceptable yield value of 56 wt.-\%. Among the activated SL-242 fibres the one with the KOH-to-fibre ratio of 3:1 was selected, because it has one of the highest $\mathrm{CO}_{2}$ micropore volumes measured in this study $\left(0.79 \mathrm{~cm}^{3} \mathrm{~g}^{-1}\right)$, a narrow micropore size distribution, and high yield. The adsorption isotherms at 298K are presented in Fig. 3 and reveal that both curves have very similar shapes and a maximum adsorption capacity of around 1 wt.- $\%$. The isotherm of the lowtemperature-carbonised fibre (SL-242) shows slightly higher adsorption, especially in the area of moderate pressures between 4 and $12 \mathrm{MPa}$. On the other hand, a considerable increase of the adsorption capacity, which would have been expected regarding the higher micropore volume, fails to appear. 
For the hydrogen adsorption measurement at $77 \mathrm{~K}$, fibres with high total pore volumes and good yield values were selected. In the case of the high-temperature-carbonised fibres (S-241) the same sample that was previously used for adsorption at room temperature was chosen, because it combines a high total microporosity $\left(0.89 \mathrm{~cm}^{3} \mathrm{~g}^{-}\right.$

${ }^{1}$ ) with feasible yield. From the set of activated low-temperature-carbonised fibres (SL-242) the one that used a $\mathrm{KOH}$-to-fibre ratio of 4:1 was measured, because it features a very high total microporosity $\left(1.13 \mathrm{~cm}^{3} \mathrm{~g}^{-1}\right)$ and a high yield value $(65 \%)$ at the same time. The two isotherms are shown in Fig. 4 and reveal that at $77 \mathrm{~K}$ and 3 MPa the maximum capacities are reached. The low-temperature-carbonised fibre (SL-242) adsorbs up to 3.8 wt.$\%$, while the maximum capacity of the high-temperature-carbonised fibre (S-241) is lower (3.2 wt.-\%), just as it is expected from their different porosities (surface areas and total micropore volumes).

It should be pointed out that the above mentioned values exclusively refer to the excess adsorption of $\mathrm{H}_{2}$ inside the pores and on the surface of the material. The total storage capacity of a tank filled with porous material can be calculated by taking into account both, compression inside the void space and excess adsorption [8,21]. The void space ratio can be estimated by: $V_{s}=1-r_{p} / r_{s}$, with $r_{p}$ being the packing density and $r_{s}$ the skeleton density of the adsorbent $[8,21]$. The packing densities of the activated carbon fibres selected for hydrogen adsorption are interesting, reaching, due to its fiber morphology, high values: $0.66 \mathrm{~g} / \mathrm{cm}^{3}$ for the sample prepared from S-241, and $0.56 \mathrm{~g} / \mathrm{cm}^{3}$ for both samples prepared from SL-242. The skeleton density is assumed to be $2.22 \mathrm{~g} / \mathrm{cm}^{3}$. Using these values, the total storage capacity for the activated S-241 fibre (carbonised at high temperature) reaches 17 g/l (2.5 wt.-\%) for $298 \mathrm{~K}$, and $31 \mathrm{~g} / 1$ (4.5 wt.-\%) at 77K. The fibres prepared from SL-242 (carbonised at low temperature) achieve values of $17 \mathrm{~g} / 1$ (2.9 wt.-\%) for the sample that was measured at 298K, and $32 \mathrm{~g} / 1$ (5.4 wt.$\%$ ) for the one measured at $77 \mathrm{~K}$. In comparison with models for idealised activated carbons the obtained storage capacities are in good agreement [22-24].

\section{Conclusions}

The present study proves, for a coal-tar-pitch-based CF, that the lowering of its carbonisation temperature, from $1273 \mathrm{~K}$ (S-241) to $973 \mathrm{~K}$ (SL-242) is clearly beneficial for its chemical activation by hydroxides. In addition to the importance of reducing the temperature, other points must be remarked. Thus, the lower carbonisation temperature reveals better porosity development and higher yield, even for lower hydroxide-to-fibre ratios. When $\mathrm{KOH}$ and $\mathrm{NaOH}$ are compared as activation agents, similar values for BET surface areas are found, whereas the obtained yield values as well as both, the total micropore volume and the volume of narrow micropores, are higher for activations that use $\mathrm{KOH}$. The prepared ACFs show quite good performance 
regarding hydrogen storage, because high hydrogen adsorption capacities and high packing densities have been reached as well as high preparation yields. At room temperature and $20 \mathrm{MPa}$ up to 1 wt.- $\%$ of hydrogen is adsorbed, and at $77 \mathrm{~K}$ a maximum hydrogen uptake of $3.8 \mathrm{wt} .-\%$ is measured at $3 \mathrm{MPa}$. These values correspond to total storage capacities at room temperature and $77 \mathrm{~K}$ of $17 \mathrm{~g} / \mathrm{l}(2.9$ wt.-\%) and $32 \mathrm{~g} / \mathrm{l}(5.4$ wt.- $\%)$, respectively. Finally, from economical aspects the activation of low-temperature-carbonised fibres has advantages as i) less energy is needed for the carbonisation at lower temperature, ii) less activation agent is necessary to develop a high porosity, and iii) the yield of the activation is considerably higher. These promising results merit further research to improve the ACFs micropore development and hence their subsequent hydrogen storage capacities.

\section{Acknowledgements}

The authors thank the European Union for financial support in the scope of the Marie Curie Research Training Network HyTRAIN (Project reference:512443), MEC (Acción complementaria; ENE2005-23824-E/CON) and the Generalitat Valenciana (Acción complementaria; ACOMP06/089) for financial help and OSAKA GAS Co. Ltd for suppling the two Donacarbo samples.

\section{References}

1. Schlapbach L, Züttel A. Hydrogen-storage materials for mobile applications. Nature 2001;414:353-358.

2. Xu, W.-C., Takahashi, K., Matsuo, Y., Hattori, Y., Kumagai, M., Ishiyama, S., Kaneko, K., Iijima, S., Investigation of hydrogen storage capacity of various carbon materials. Int. J. Hydrogen Energy 2007;32(13):2504-2512.

3. Jordá-Beneyto, M., Lozano-Castelló, D., Suárez-García, F. Cazorla-Amorós, D., Linares-Solano, A. Advanced activated carbon monoliths and activated carbons for hydrogen storage. doi:10.1016/j.micromeso.2007.09.034.

4. Darkrim Lamari, F., Aoufi, A., Levesque, D. Quantum contribution to gas adsorption in carbon nanotubes. Mol. Sim. 2000;24(1-3):51-61.

5. Lozano-Castelló D, Lillo-Ródenas MA, Cazorla-Amorós D, Linares-Solano A. Preparation of activated carbons from Spanish anthracite - I. Activation by KOH. Carbon 2001;39(5):741-749.

6. Lillo-Ródenas MA, Lozano-Castelló D, Cazorla-Amorós D, Linares-Solano A. Preparation of activated carbons from Spanish anthracite - II. Activation by NaOH. Carbon 2001;39(5):751-759.

7. de la Casa-Lillo MA, Lamari-Darkrim F, Cazorla-Amorós D, Linares-Solano A. Hydrogen storage in activated carbons and activated carbon fibers. J Phys Chem B 2002;106(42):10930-10934. 
8. Jordá-Beneyto M, Suárez-García F, Lozano-Castelló D, Cazorla-Amorós D, Linares-Solano A. Hydrogen storage on chemically activated carbons and carbon nanomaterials at high pressures. Carbon 2007;45(2):293303.

9. Figueroa-Torres MZ, Robau-Sánchez A, de la Torre-Sáenz L, Aguilar-Elguézabal A. Hydrogen adsorption by nanostructured carbons synthesized by chemical activation. Micropor Mesopor Mater 2007;98(1-3):89-93.

10. Maciá-Agulló JA, Moore BC, Cazorla-Amorós D, Linares-Solano A. Influence of carbon fibres crystallinities on their chemical activation by $\mathrm{KOH}$ and NaOH. Micropor Mesopor Mater 2007;101(3):397-405.

11. Pierson HO. Handbook of Carbon, Graphite, Diamond and Fullerenes. Park Ridge, New Jersey, U.S.A.: Noyes Publications, 1993.

12. Dubinin MM. The potential theory of adsorption of gases and vapors for adsorbents with energetically nonuniform surfaces. Chem Rev 1960;60(2):235-241.

13. Cazorla-Amorós D, Alcañiz-Monge J, Linares-Solano A. Characterization of Activated Carbon Fibers by $\mathrm{CO}_{2}$ Adsorption. Langmuir 1996;12(11):2820-2824.

14. Lozano-Castelló D, Cazorla-Amorós D, Linares-Solano A. Usefuness of $\mathrm{CO}_{2}$ adsorption at $273 \mathrm{~K}$ for the characterization of porous materials. Carbon 2004;42(7):1233-1242.

15. Sing KSW, Everett DH,. Haul RAW, Moscou L, Pierotti RA, Rouquerol J, Siemieniewska T. Reporting physisorption data for gas/solid systems with special reference to the determination of surface area and porosity. Pure and Appl Chem 1985;57(4):603-619.

16. Maciá-Agulló JA, Moore BC, Cazorla-Amorós D, Linares-Solano A. Activation of coal tar pitch carbon fibres: Physical activation vs. chemical activation. Carbon 2004;42(7):1367-1370.

17. Texier-Mandoki N, Dentzer J, Piquero T, Saadallah S, David P, Vix-Guterl C. Hydrogen storage in activated carbon materials: Role of the nanoporous texture. Carbon 2004;42(12-13):2735-2747.

18. Hirscher M, Panella B. Nanostructures with high surface area for hydrogen storage. J Alloys Compd 2005;404-406:399-401.

19. Panella B, Hirscher M, Roth S. Hydrogen adsorption in different carbon nanostructures. Carbon 2005;43(10):2209-2214.

20. Gadiou R, Saadallah S-E, Piquero T, David P, Parmentier J, Vix-Guterl C. The influence of textural properties on the adsorption of hydrogen on ordered nanostructured carbons. Micropor Mesopor Mater 2005;79(1-3):121-128.

21. Zhou L, Zhou Y, Sun Y. Enhanced storage of hydrogen at the temperature of liquid nitrogen. Int J Hydrogen Energy 2004;29(3):319-322. 
22. Kayiran, S.B., Lamari Darkrim F., Levesque, D. Adsorption properties and structural characterization of activated carbons and nanocarbons. J. Phys. Chem. B 2004;108 (39):15211-15215.

23. Bénard P, Chahine R. Modeling of adsorption storage of hydrogen on activated carbons. Int $\mathrm{J}$ Hydrogen Energy 2001;26(8):849-855.

24. Darkrim Lamari, F., Vermesse, J., Malbrunot, P., Levesque, D. Monte Carlo simulations of nitrogen and hydrogen physisorption at high pressures and room temperature. Comparison with experiments. J. Chem. Phys. 1999;110(8):4020-4027. 


\section{FIGURE CAPTIONS:}

Figure 1. $\quad \mathrm{N}_{2}$ isotherms of fibres (S-241, carbonised at $1273 \mathrm{~K}$ ) that were activated with $\mathrm{KOH}$ and $\mathrm{NaOH}$ using different hydroxide-to-fibre ratios (wt:wt).

Figure 2. $\quad \mathrm{N}_{2}$ isotherms of fibres (SL-242, carbonised at 973K) that were activated with $\mathrm{KOH}$ and $\mathrm{NaOH}$ using different hydroxide-to-fibre ratios (wt:wt).

Figure 3. $\mathrm{H}_{2}$ excess adsorption isotherms measured at room temperature for fibres activated using both precursors (S-241 and SL-242, carbonised at 1273K and 973K, respectively) and different KOH-to-fibre ratios (wt:wt).

Figure 4. $\quad \mathrm{H}_{2}$ excess adsorption isotherms measured at $77 \mathrm{~K}$ for fibres activated using both precursors (S241 and SL-242, carbonised at $1273 \mathrm{~K}$ and $973 \mathrm{~K}$, respectively) and different KOH-to-fibre ratios (wt:wt). 


\section{Table 1}

Porous texture characterisation and yield values for chemically activated carbon fibres and the unactivated precursors

\begin{tabular}{ccccccc}
\hline $\begin{array}{c}\text { Carbonisation } \\
\text { temperature / K }\end{array}$ & $\begin{array}{c}\text { Activation } \\
\text { agent }\end{array}$ & $\begin{array}{c}\text { Ratio } \\
(\mathrm{wt}: \mathrm{wt})\end{array}$ & $\begin{array}{c}\mathrm{BET} \text { surface area / } \\
\mathrm{m}^{2} \mathrm{~g}^{-1}\end{array}$ & $\begin{array}{c}\mathrm{V}_{\mathrm{DR}}\left(\mathrm{N}_{2}\right) / \\
\mathrm{cm}^{3} \mathrm{~g}^{-1}\end{array}$ & $\begin{array}{c}\mathrm{V}_{\mathrm{DR}}\left(\mathrm{CO}_{2}\right) / \\
\mathrm{cm}^{3} \mathrm{~g}^{-1}\end{array}$ & $\begin{array}{c}\text { Yield / } \\
\text { wt.-\% }\end{array}$ \\
\hline 1273 & - & - & 0 & 0 & 0.08 & - \\
1273 & $\mathrm{KOH}$ & $3: 1$ & 1288 & 0.59 & 0.57 & 74 \\
1273 & $\mathrm{KOH}$ & $4: 1$ & 1456 & 0.67 & 0.55 & 72 \\
1273 & $\mathrm{KOH}$ & $6: 1$ & 1894 & 0.89 & 0.65 & 56 \\
1273 & $\mathrm{KOH}$ & $10: 1$ & 1937 & 0.84 & 0.53 & 34 \\
1273 & $\mathrm{NaOH}$ & $4: 1$ & 1604 & 0.71 & 0.55 & 51 \\
1273 & $\mathrm{NaOH}$ & $10: 1$ & 2633 & 0.99 & 0.54 & 6 \\
973 & - & - & 7 & 0 & 0.11 & - \\
973 & $\mathrm{KOH}$ & $2: 1$ & 1431 & 0.71 & 0.65 & 80 \\
973 & $\mathrm{KOH}$ & $3: 1$ & 2004 & 0.94 & 0.79 & 74 \\
973 & $\mathrm{KOH}$ & $4: 1$ & 2472 & 1.13 & 0.71 & 65 \\
973 & $\mathrm{KOH}$ & $5: 1$ & 2888 & 1.23 & 0.80 & 55 \\
973 & $\mathrm{NaOH}$ & $2: 1$ & 1405 & 0.63 & 0.47 & 73 \\
973 & $\mathrm{NaOH}$ & $4: 1$ & 2513 & 1 & 0.61 & 50 \\
\hline
\end{tabular}




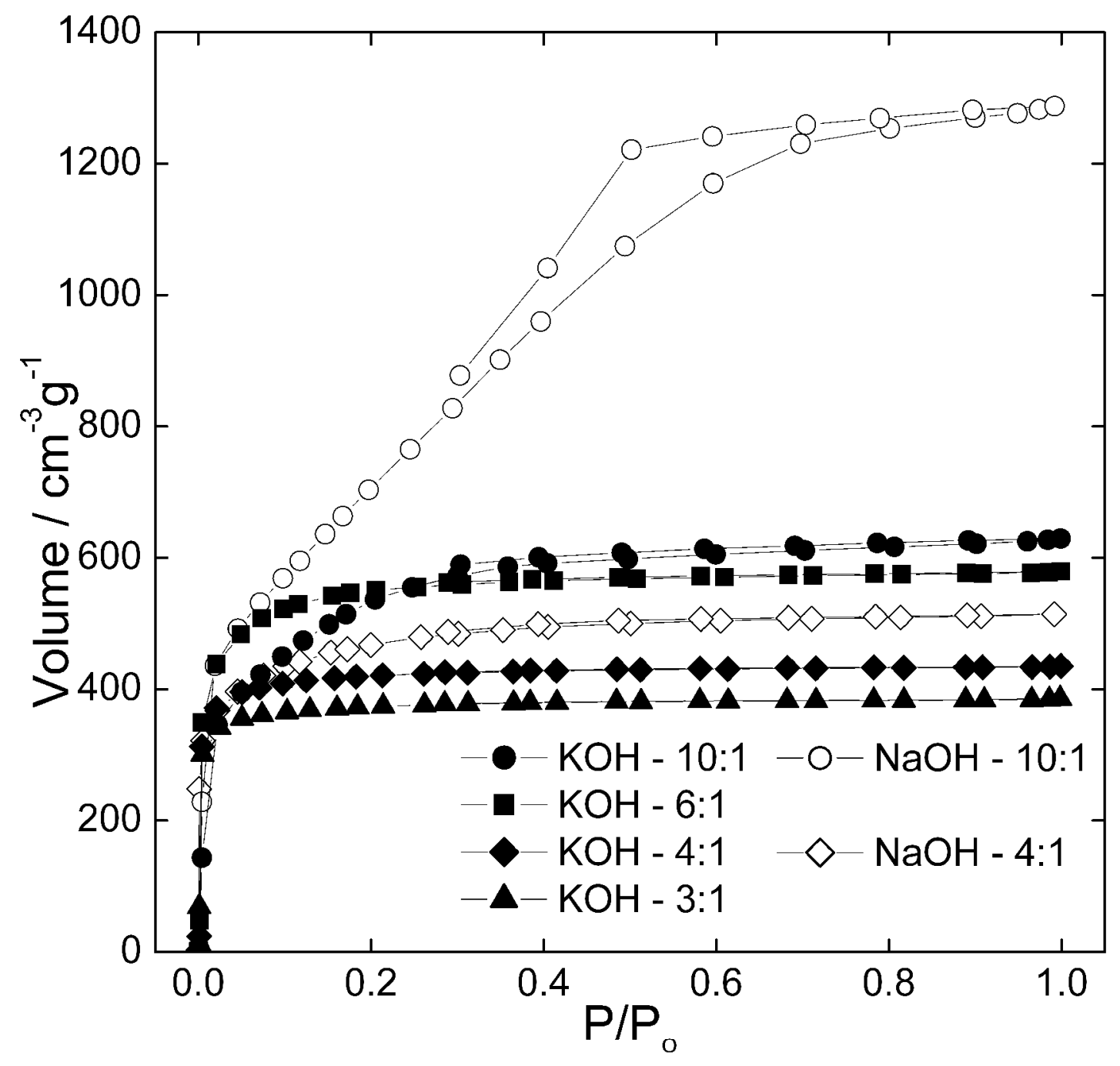




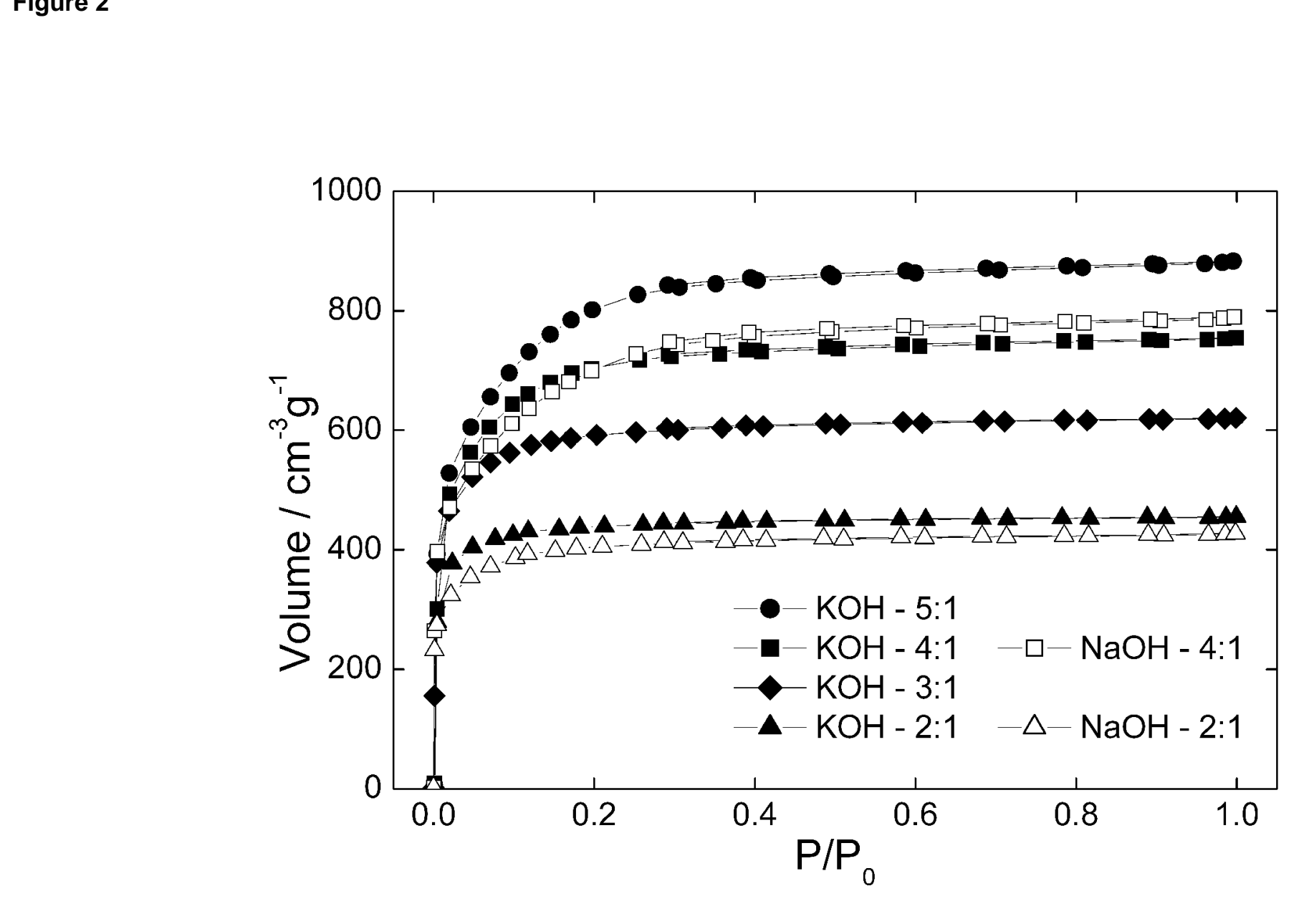

Figure 2

(⿸丆口 \\ .}

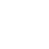
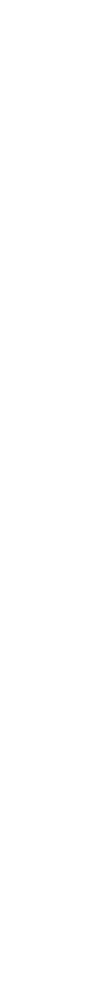

.

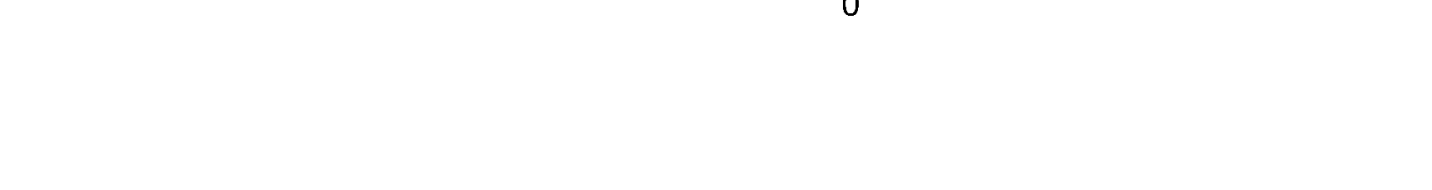


Figure 3

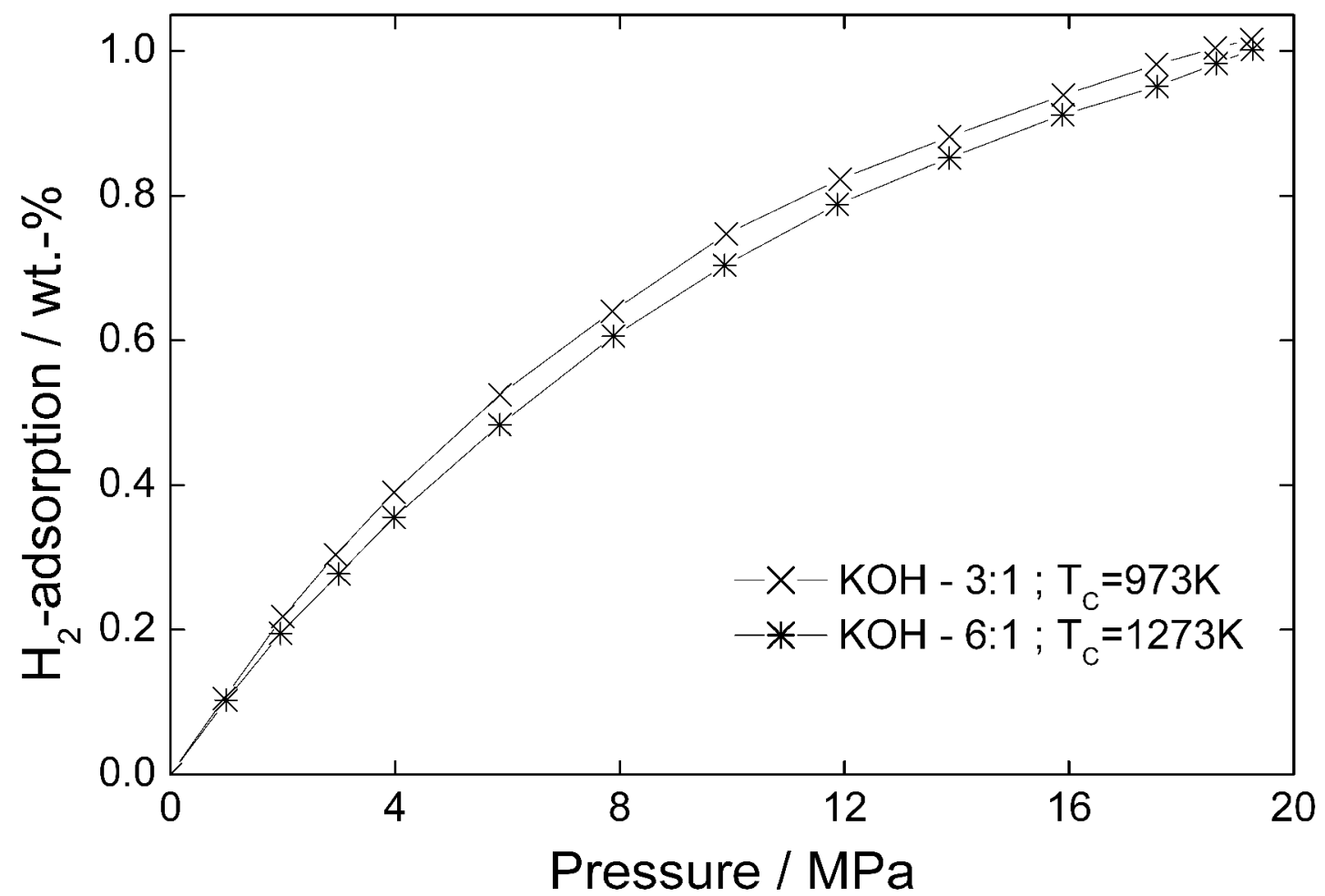


